\title{
Correctional Education and Child-Rearing with Visual Impairment Through Work Involvement
}

\author{
Sergey Yekimov ${ }^{1},{ }^{*}$ Aleksey Masenko², Natalia Grankina ${ }^{2}$, Irina Gerasimenko ${ }^{3}$, \\ Elena Udina ${ }^{4}$
}

\author{
${ }^{1}$ Publishing House "Education and Science", Russia \\ ${ }^{2}$ Federal State Budgetary Educational Institution of Higher Education "Kuban State Agrarian University named after \\ I.T. Trubilin", Russia \\ ${ }^{3}$ Tula State Leo Tolstoy Pedagogical University, Russia \\ ${ }^{4}$ Sevastopol State University, Russia \\ *Email: rusnauka@email.cz
}

\begin{abstract}
This article examines the problem of correctional education and upbringing of children with visual impairments by attracting them to work. It is shown that introducing visually impaired children to work improves their sensorimotor skills, and their presence will be necessary for them in their future profession. The formation of a visually impaired person's personality primarily depends on the attitude towards disabled people in society. This study examined the effect of wool felting on children's sensorimotor skills. The study results showed that felting in children's labour education could improve their sensorimotor skills, gain self-confidence, and instil a love of labour efficiency.
\end{abstract}

Keywords: Felting from wool, Children's labour education, Children with visual and hearing disabilities, Children's education, Children's creativity.

\section{INTRODUCTION}

Modern trends in the development of correctional pedagogy are characterised by individualisation and differentiation of children's education. The primary attention of pedagogical-correctional and educationaleducational processes focuses on the child's specific personality, considering the peculiarities of his development, the propensity for cognition, and other points. According to Volodymyr Onopriienko (2016), this makes it possible to effectively solve correctional support problems for children with various developmental disorders.

According to Adrian Wallwork (2018), the main principles based on which the pedagogical-correctional and educational processes should proceed are:

- Differentiated (pedagogical and psychological, physiological and clinical approach to implementing corrective assistance and diagnostics).
- A detailed account of the individual, general and specific characteristics of the child's development.

- Providing the necessary conditions for the education, treatment and education of children with visual impairments.

- Creation of conditions for self-realisation of children and their social adaptation.

T. Antonenko and G. Shevchenko (2020), E. Strebeleva, Svetlana Lazurenko and L. Kuzenkova (2012) in their articles, correctional work should be carried out in parallel with the course of the general educational process. All lessons should be individualised, depending on the child's needs.

An important place between such events should be given to educational work, which would correlate with the pedagogical and correctional process principles $\mathrm{N}$. Mokhnatkin (2015). 
According to E. Strebeleva (1998), because recently the number of children with various kinds of disorders of their psycho-emotional development, such as hostility, anxiety, emotional instability, aggressive behaviour, as well as the presence of fears, has increased, this is with an emotional deficiency in children with visual impairments. This, in turn, maybe the reason for the manifestation of psychological and social maladjustment and unsatisfactory interaction with others.

As per the opinions of I.A. Belozerova (2019), Iryna Voronchuk (2016), Patrick O'Meara (2003), feelings and emotions are a kind of psychological states and processes that correlate with interests, motives of activity and needs concerning oneself and other people. Feelings and emotions depend on the completeness and accuracy of the child's understanding of the world around him.

The wealth of a child's emotional world depends on his ability to perceive the world around him. The presence of visual impairments in children harms their thinking, perception, and representation, thereby narrowing their emotional sphere as per Rogelio DiazGuerrero and Lorand Szalay (1991) opinion, Zora Jachova, Elizabet SOLTIROVA, Slavica IKONOMOVA, Natasa CICEVSKA and Natasa GJEORGIEVA (1997).

According to Przemysław Przybylski (2019), teachers in their daily activities regularly deal with problems that are related to the children's emotional sphere. To solve which, it is necessary to have a comfortable, educational environment that would be a source of knowledge for the child and contribute to the acquisition of social experience and the development of him as a person. And this, in turn, improves communication with adults and peers, the appearance of adequate and positive self-esteem, the manifestation of anxiety decreases, and the manifestation of undesirable behaviour forms become less.

Labour education is purposeful work to inculcate a love for work and the need for it and respect other people's work.

Tojiboeva Gulkhumor, Ismoilov Usmonjon (2020), Marchuk Oksana (2020), Przybylski Przemysław (2019) in their articles, states that the labour education of children should be:

- To cultivate diligence, independence, the need for work.

- Teach various labour skills and abilities.

- To acquaint adults with work and to foster respect for it.

- To instil a love for socially oriented motives of work.
As Oksana Marchuk noted in her works (2020), labour education of children with visual impairments should be:

- To assist in the formation of an active child's life position.

- Promote the formation of skills in orientation in space.

- To prepare for the upcoming participation in labour activities.

Suppose children have a visual impairment, arisen because of their psychophysical characteristics and parental care. In that case, they often have a dull desire to work for the common good and the consumer attitude towards others may prevail.

Consequently, these children may develop poor selfcare skills; there is a violation of movement coordination and insufficient skills in orientation in space. Also, there may be no daily need for work and the desire and habit to work, and, therefore, they have poorly developed human qualities such as independence, hard work and activity.

Therefore, in her research E. Strebeleva (1998), indicate that labour education should be carried out considering the possibilities of children with visual impairments, and special attention should be paid to the formation of their independence.

According to Snežana Štrbac (2011), visually impaired children do not have spontaneously correct ideas about the goals and purpose of the work of others, they do not always have a sense of due gratitude and respect even to those around them, whose work is associated with caring for these children.

According to Doret Ruyter (2018), to educate a child with visual impairments of a sense of responsibility and duty to the people around them, it is necessary to continually complicate the assignments, reinforcing their fulfilment with a benevolent, positive assessment. Correctional and educational work should begin with an introduction to labour activity and familiarisation with the tools of the labour themselves and the way of managing them. In the process of educational and correctional work, their actions are cognitive.

\section{METHODS}

During this research, an analytical research method was used. This made it possible to study the problems investigated in this scientific work in their unity and development. Considering the goals and objectives of the study, the functional-structural method of scientific research was applied. This type of method provided an opportunity to study some of the problems associated with children's upbringing with visual impairment and corrective education in general. 


\section{RESULTS}

In 2018, we were approached by the director of the specialised preschool educational institution No. 3 in Kharkiv, which specialises in working with children with special educational needs and visual and hearing defects. He said that due to insufficient budget funding, the educational institution does not have the opportunity to purchase expensive equipment and asked to develop training sessions to be able to carry out educational activities, based on the financial resources that it's preschool educational institution has.

Before starting the study, we surveyed parents of children who attend this educational institution. The survey results showed that children spend a lot of time playing games on their computer or tablet. This does not contribute to solving health problems. Therefore, we decided to develop a set of training sessions for students of this educational institution, which on the one hand was held playfully, and on the other hand, helped children develop and keep up with their peers. As an alternative to computer technology in the educational process, we suggested using classes related to needlework, namely felting from wool, in this preschool institution. On the one hand, this made it possible to achieve the required educational result. On the other hand, it was not burdensome for the financial capabilities of the preschool educational institution.

The number of children suffering from strabismus, farsightedness, myopia and amblyopia is steadily increasing from year to year. Early diagnosis allows not only to start treatment on time but also with teachers and psychologists' help to prevent deviations in the child's development.

Since a sharp deterioration in vision limits the child's ability to learn about the world around them, this negatively affects the development of imagination, speech and memory. Also, such children's active motor activity is usually limited, because of which many of them suffer from impaired posture, hypodynamia, flat feet, and a violation of the cardiovascular system.

Therefore, in our opinion, for children with visual impairments, classes should be conducted that develop their vision, while correcting violations of touch and speech, developing hand and finger movements. Simultaneously, all educational games and tasks should be selected individually, based on the child's visual state.

Visual defects negatively affect the child's cognitive abilities and allow him to get complete information about the surrounding reality. Although not full vision does not give children the necessary reflection of the surrounding world, the visual analyser plays an essential role in the child's knowledge of the surrounding reality.

Because children do not fully understand their deficiency features, they have specific difficulties in understanding themselves, their body's features and capabilities, and usually, they do not try to use other senses to replenish and enrich their sensory experience.

At the same time, a blind person, due to compensatory development, usually feels and hears the world around him better, and his sensory capabilities, as a rule, exceed those of a sighted person.

In our opinion, correctional work with children with vision disorders considering features of their perception of the world around, allows to obtain good results in their training and education, forms the basis of their social adaptation and preparation for future life. In such special classes, children develop skills to effectively use their impaired vision capabilities, complement visual perception with other modalities' perceptions, improve their mental activity, and develop cognitive activity.

The most important task of education and training of children with special educational needs is to stimulate the formation of labour skills that will allow them to achieve socialisation and adaptation in society further.

These children's intellectual and physical abilities are limited; each child has its dynamics and development pace. Many of these children have disability status and appropriate social security.

In this regard, but in our opinion, such children should be taught to work, considering their individual physical and psychological characteristics.

Stimulating motivation can be one of the most effective ways to increase the need for work. This, in our opinion, can be achieved by instilling respect for the results of work and awareness of its necessity. Children should understand that their work is needed by others and by themselves.

Making children various crafts with their own hands help them form and develop creative activity and meaning, which positively affects their emotions. Also, detailed manual work brings up in them patience, hard work, perseverance and attention.

Working activities should be as diverse as possible, but considering children's capabilities, in our opinion, weaving and felting from the wool may be the most suitable for such activities.

Good vision is not necessary for weaving. Moreover, blind people can engage in weaving, and at the same time, create beautiful products. When weaving, you do not need to have a lot of hand strength, and the quality of work depends on the technique of doing the work.

Teaching children to make wool products (felting) can have excellent therapeutic value. Wool has properties that can be used when working with children with various disabilities. Also, when working with it, children have the opportunity to apply the skills acquired in drawing lessons. 
When working with children with wool, two aspects can be distinguished: technical and creative. Mastering the techniques of making products from thread and wool, they improve their creative abilities and create artistic products in their production process.

Children's wool crafts can be used as decorative ornaments, souvenirs. The result of the work done brings children many positive emotions and increases selfconfidence and interest in work.

Felting is a simple sequence of several separate technological operations. Children learn all these operations, but with varying degrees of independence in performing operations. With each new product, adult participation decreases and student participation increases.

In our opinion, there is no universal method of teaching children with visual impairments. Simultaneously, the fundamental principles applied in the educational process with such children can be the basic principles of artistic education and labour training.

Education of labour skills through the manufacture of products made of wool and vines, in our opinion, can find its application in the lessons of labour training in correctional educational institutions.

Wool felting classes were held in a preschool for 6 months. During this time, they mastered the basics of felting from wool and were able to make the simplest New Year's toys and gifts to their mothers and grandmothers under teachers' guidance.

After that, we re-conducted a survey of parents of pupils of a preschool educational institution. Which showed that felting wool brings children a lot of positive emotions, encourages creativity and increases their selfconfidence.

\section{DISCUSSION}

Studies have shown that after classes with labour education elements, the speech of children with visual impairments becomes better and more affluent.

Children with special educational needs, under certain conditions, have the opportunity to acquire work skills. In our opinion, a child's involvement in work activity can be achieved if the child has a positive attitude to what the adult is doing. An essential feature of upbringing and labour training is that it should be differentiated.

The main task of visually impaired children's development is to systematically and purposefully develop their emotional responsiveness, imagination, the need for work, creative thinking, and aesthetic taste.

If visually impaired children are included in work through sculpting from wool weaving, their sensory- motor skills improve, which is essential in their future profession.

Distinctive features of the formation as a personality of a person with visual impairments are determined not only by the presence of a defect but also by the attitude towards disabled people in society.

\section{CONCLUSIONS}

In our opinion, for the successful formation of a propensity to work in a visually impaired child, the following conditions must be met:

- Provide psychological comfort, establish contact with teachers and adults.

- Stimulate children's physical activity with a gradual increase in the child's participation in joint work activities.

- Provide conditions, place, attributes and time for the performance of work.

- Provide children with a sense of success when completing assignments.

- Provide support and external control during the execution of orders.

- Expand children's experience as a basis for the transition to more complex independent activities.

During the upbringing of visually impaired children through labour training, they develop an active social position. Education and labour education are essential for correction and compensation, impaired and underdeveloped functions, and children's preparation for the forthcoming labour activity.

Therefore, in our opinion, labour education should take an essential place in the educational process in educational institutions with visual impairments.

The study results showed that felting in children's labour education could improve their sensorimotor skills, gain self-confidence, and instil a love of labour efficiency.

Felting from wool requires more skills from children than drawing and at the same time does not require expensive materials and equipment and can be implemented in any preschool educational institution.

\section{REFERENCES}

[1] T. Antonenko and G. Shevchenko, Harmonious unity of spirituality, culture, education and upbringing, All Ukrainian scientific-practical magazine Principal of School Liceum Gymnasium 2020, pp. 95-107. DOI: https://doi.org/10.37836/2309-7744-2020-1-9 
[2] I.A. Belozerova, Coevolutionary approach in the system of ecological education and upbringing, Modern High Technologies 2 (2019) 314-8. DOI: https://doi.org/10.17513/snt.37810

[3] Diaz-Guerrero Rogelio and Szalay Lorand, 1991, Education, Upbringing. https://doi.org/10.1007/978-1-4899-0733-2_9

[4] Zora Jachova, Elizabet Soltirova, Slavica Ikonomova, Natasa Cicevska and Natasa Gjeorgieva, 1997, Pre-school upbringing of children with developmental difficulties-condition for successful integrational education, Journal of Special Education and Rehabilitation 1.

[5] Oksana Marchuk, The main directions of upbringing of children and young people in the educational and cultural institutions of the Volyn, Bulletin of Oleksandr Dovzhenko Hlukhiv national pedagogical university 42 (2020) 206-213. DOI: https://doi.org/10.31376/2410-0897-2020-1-42206-213

[6] N. Mokhnatkin, Artistic and aesthetic concepts of children's education and upbringing: traditions and innovations, 2015, 330-331. DOI: https://doi.org/10.15216/RGSU-XIV-330

[7] Patrick O'Meara, 2003, Education and Upbringing. DOI: https://doi.org/10.1057/9780230504608_2

[8] Onopriienko Volodymyr, Target functions of environmental education and upbringing, Scientific Journal of Polonia University 19 (2016) 115-121. DOI: https://doi.org/10.23856/1912

[9] Przemysław Przybylski, A New Model of Education and Upbringing in Polish School, 21st Century Pedagogy 3 (2019) 35-41. DOI: https://doi.org/10.2478/ped21-2019-0005

[10] Doret Ruyter, Well-Being and the Upbringing and Education of Children, 2018. DOI: https://doi.org/10.1007/978-3-319-72761-5_66

[11] Snežana Štrbac, Environmental education and upbringing, Journal of environmental protection and ecology 12 (2011) 2341-2346.

[12]E. Strebeleva, The Modern Approach to the Preschool Upbringing of Children with Abnormalities in Development, Russian Education \& Society 40 (1998) 73-90. DOI: https://doi.org/10.2753/RES1060-9393400873

[13]E. Strebeleva, Svetlana Lazurenko and L. Kuzenkova, Children with cognitive development disorder: rehabilitation by means of education, Pediatric pharmacology 9 (2012) 80. DOI: https://doi.org/10.15690/pf.v9i6.522
[14] Gulkhumor Tojiboeva and Usmonjon Ismoilov, The psychological peculiarities of teenage conflict in the process of education and upbringing, Theoretical \& Applied Science 81 (2020) 78-82. DOI: https://doi.org/10.15863/TAS.2020.01.81.16

[15] Iryna Voronchuk, Early Modern Era Intellectuals on Education and Upbringing of Children, Ukrainian Studies 1(58) (2016) 71-88. DOI: https://doi.org/10.30840/24137065.1(58).2016.150915

[16]Adrian Wallwork, Education Background, Upbringing, Manners, Training, 2018. DOI: https://doi.org/10.1007/978-3-319-70981-9_26 